\title{
Is Hypoglossal Nerve Palsy Caused by Craniocervical Junction Degenerative Disease an Underrecognized Entity?
}

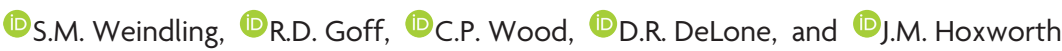

\begin{abstract}
SUMMARY: Isolated hypoglossal nerve palsy is uncommon, and underlying craniocervical junction degenerative disease has rarely been reported as an underlying cause. To improve understanding of this entity, we present a retrospective series of 18 patients with hypoglossal palsy in whom twelfth cranial nerve compression within the premedullary cistern or hypoglossal canal, or both, was found secondary to craniocervical junction juxta-articular cysts, retro-odontoid fibrous pseudotumors, and osteophytes. The imaging techniques and characteristic craniocervical junction degenerative disease lesion imaging findings presented here might help clinicians interpreting hypoglossal palsy imaging studies avoid perceptual and interpretive errors commonly found in the present series.
\end{abstract}

ABBREVIATIONS: $C C$ J = craniocervical junction; $C$ CJDD = craniocervical junction degenerative disease; JAC = juxta-articular cyst; ROFP = retro-odontoid fibrous pseudotumor

$\mathrm{H}$ ypoglossal nerve palsy is an infrequent clinical presentation, most commonly occurring in combination with other lower cranial nerve palsies. By using a segmental approach, ${ }^{1}$ the underlying etiologic factors can be subdivided by location as involving the brain stem, premedullary cistern, skull base, nasopharynx or oropharynx, or sublingual regions. Hypoglossal nerve palsy secondary to craniocervical junction (CCJ) juxta-articular (synovial and ganglion) cysts $^{2-8}$ and osteophytes ${ }^{9,10}$ has been described in isolated case reports; yet, these pathologies are not classically included in the differential diagnosis for hypoglossal palsy. Distinguishing CCJ degenerative lesions from other hypoglossal nerve pathologies might have important diagnostic and treatment implications. To improve understanding of this disorder, a case series of 18 patients with hypoglossal palsy and ipsilateral twelfth cranial nerve compression secondary to CCJ juxta-articular cysts

Received March 11, 2016; accepted after revision May 30.

From the Department of Radiology (S.M.W., R.D.G.), Mayo Clinic, Jacksonville, Florida; Department of Radiology (C.P.W., D.R.D.), Mayo Clinic, Rochester, Min nesota; and Department of Radiology (J.M.H.), Mayo Clinic Hospital, Phoenix, Arizona.

Paper previously presented at: Annual Meeting of the American Society of Head and Neck Radiology, September 9-13, 2015; Naples, Florida.

Please address correspondence to Steven M. Weindling, MD, Department of Radiology, Mayo Clinic, 4500 San Pablo Rd, Jacksonville, FL 32224; e-mail: weindling.steven@mayo.edu

三 Indicates article with supplemental on-line tables.

http://dx.doi.org/10.3174/ajnr.A4885
(JACs), retro-odontoid fibrous pseudotumors (ROFPs), and osteophytes is presented.

\section{CASE SERIES}

\section{Patients}

This Health Insurance Portability and Accountability Act-compliant retrospective case series was approved by the Mayo Clinic Institutional Review Board. Initially, 4 neuroradiologists (S.M.W., C.P.W., D.R.D., J.M.H.) provided 7 known cases of hypoglossal palsy secondary to craniocervical junction degenerative disease (CCJDD) from their teaching files. Next, a retrospective Boolean search of radiology reports from 3 affiliated tertiary medical centers between January 1, 2005, and December 31, 2014, was performed, combining the words "hypoglossal" or "tongue" and "palsy," "atrophy," or "denervation." From this list, patients were excluded if hypoglossal palsy could not be confirmed through review of the electronic health record. Patients with prior head and neck or skull base tumor, radiation therapy, or surgery also were excluded. For the remaining patients with hypoglossal palsy, imaging studies that included the CCJ were reviewed for possible twelfth cranial nerve compression by an underlying CCJDD lesion (JAC, ROFP, or osteophyte). Eleven additional cases were discovered from this 10 -year multicenter retrospective review. Three physicians with neuroradiology subspecialty board certification (S.M.W., C.P.W., J.M.H.) performed a consensus imaging review for all patients with hypoglossal palsy believed secondary to CCJDD to confirm and characterize the offending lesions. For 
each patient with hypoglossal palsy caused by CCJDD, our institution's first MR imaging or CT report was reviewed to ascertain whether the initial differential diagnosis included the consensus diagnosis.

\section{Clinical Findings}

A total of 18 patients with hypoglossal palsy related to CCJDD were included in this case series ( 12 women and 6 men; mean age, 74 years; range, 52-89 years). Symptoms at presentation to our institutions most commonly included tongue weakness or deviation (13/18), dysarthria (12/18), and dysphagia (6/18) (On-line Table 1). Neurologic examination confirmed hypoglossal palsy in all patients. Among the 4 patients in whom the underlying lesion was addressed surgically, the duration between symptom onset and surgery was 3 months $(n=1), 11$ months $(n=2)$, and 7 years $(n=1)$, respectively. In the final patient, surgical delay was due to lesion misdiagnosis as a hypoglossal schwannoma until the correct diagnosis of JAC was rendered 1 month before surgery. New-onset or worsening headache or suboccipital pain was an associated concern for 13 patients. No patient had a history of rheumatoid arthritis, psoriatic arthritis, gout, or calcium pyrophosphate deposition disease.

\section{Imaging Findings}

For the 18 patients with CCJDD hypoglossal palsy, the brain, head and neck, and cervical spine imaging studies from our institution and outside facilities spanning 12 years included $17 \mathrm{MR}$ imaging (15 with contrast medium) and 12 CT scans using diverse techniques. Underlying CCJDD lesions included atlanto-occipital JACs $(n=10)$, atlantoaxial JACs $(n=2)$, ROFPs $(n=4)$, and
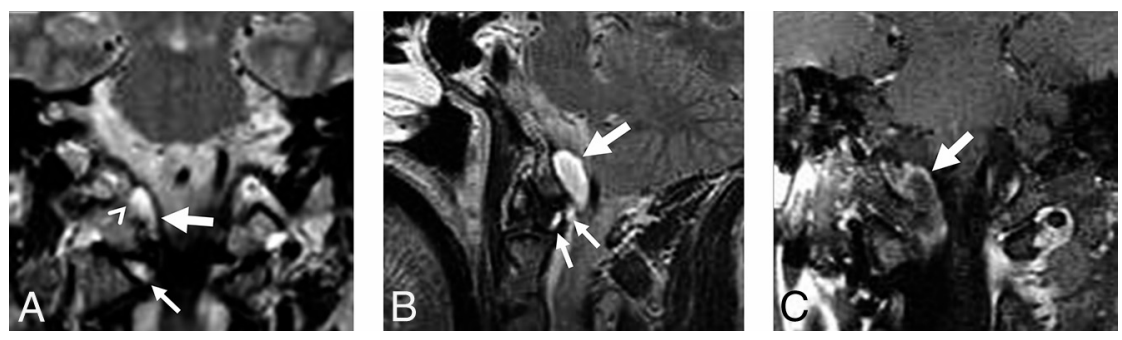

FIG 1. Cl-occipital JAC encroaching on the hypoglossal canal internal ostium of patient 1. The patient was a 56-year-old man with a 3-month history of tongue weakness. The T2-hyperintense JAC (large arrows) encroachment of the hypoglossal canal internal ostium (arrowhead) and lobular cyst projections (small arrows) from the Cl-occipital joint are best seen on T2-weighted coronal $(A)$ and sagittal $(B)$ images. C, Postcontrast T1-weighted coronal image shows JAC thin rim enhancement (large arrow).
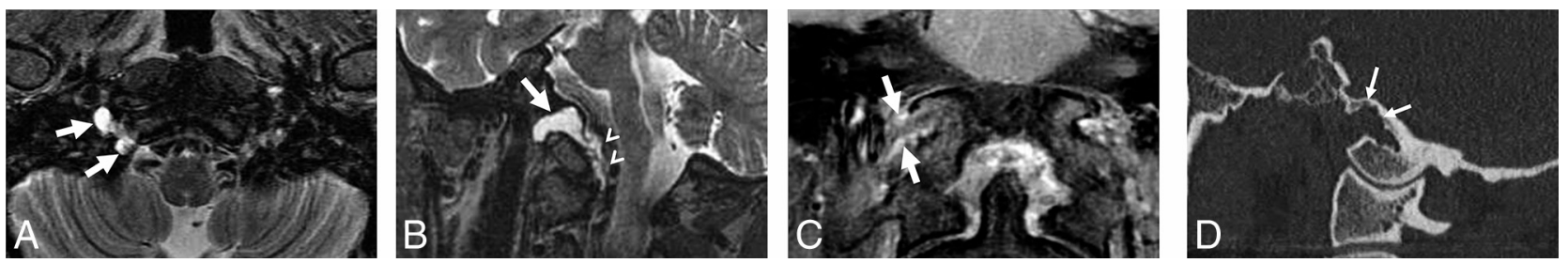

FIG 2. Cl-occipital JAC extending into hypoglossal canal of patient 12. The patient was a 64-year-old man with a 9-month history of tongue weakness, dysarthria, and dysphagia. A, MR T2-weighted axial image shows an extradural hyperintense JAC with a thin hypointense rim extending through the hypoglossal canal (large arrows). B, Oblique T2-weighted image parallel to the hypoglossal canal shows the JAC extension through the hypoglossal canal (large arrow) and contiguity with the Cl-occipital joint through a thin lobular extradural projection (arrowheads). C, Postcontrast T1-weighted coronal image shows cyst rim enhancement (large arrows). D, CT sagittal bone reconstruction at the hypoglossal canal external ostium shows secondary canal widening (arrows). 

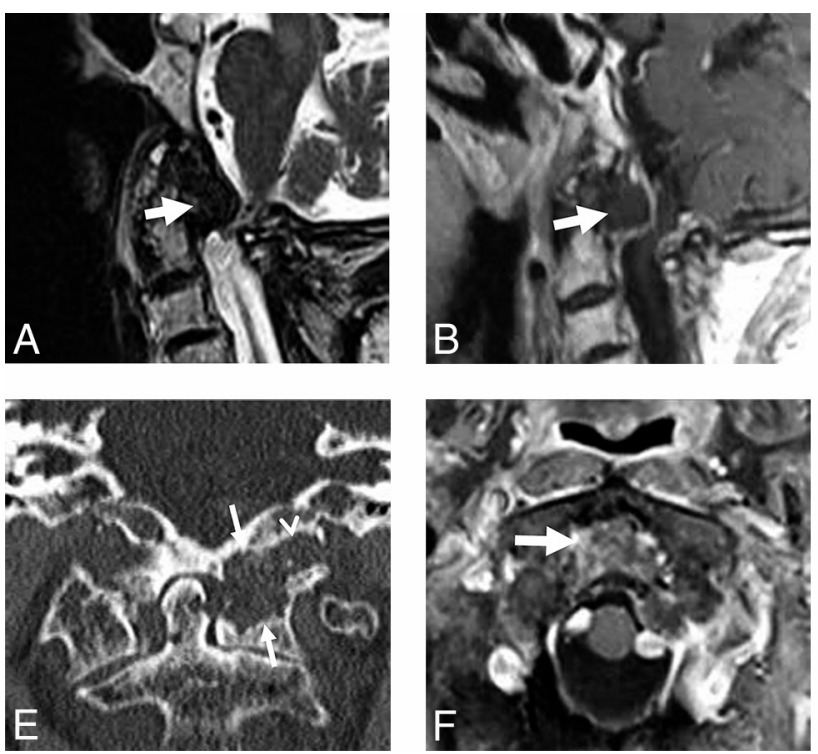
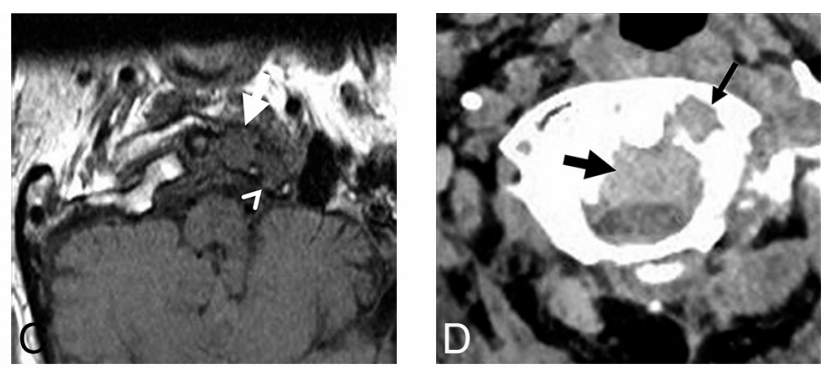

FIG 3. Retro-odontoid pseudotumor of patient 2. This patient was an 87-year-old woman with a 2-month history of dysphagia. MR imaging sagittal views show the retro-odontoid soft tissue mass (large arrows) to be T2 hypointense $(A)$, and nonenhancing (B). C, Axial T1-weighted image shows isointense soft tissue eroding the skull base (large arrow) with encroachment of the hypoglossal canal (arrowhead). CT axial soft tissue $(D)$ and coronal bone (E) reformations show hyperattenuated pseudotumor mass ( $D$, large arrow) causing bone erosions (small arrows), with extension into the hypoglossal canal ( $E$, arrowhead). F, For patient 8 , axial enhanced 7 -weighted image shows retro-odontoid mass heterogeneous enhancement (arrow), as seen in 3 of our 4 patients with ROFPs.
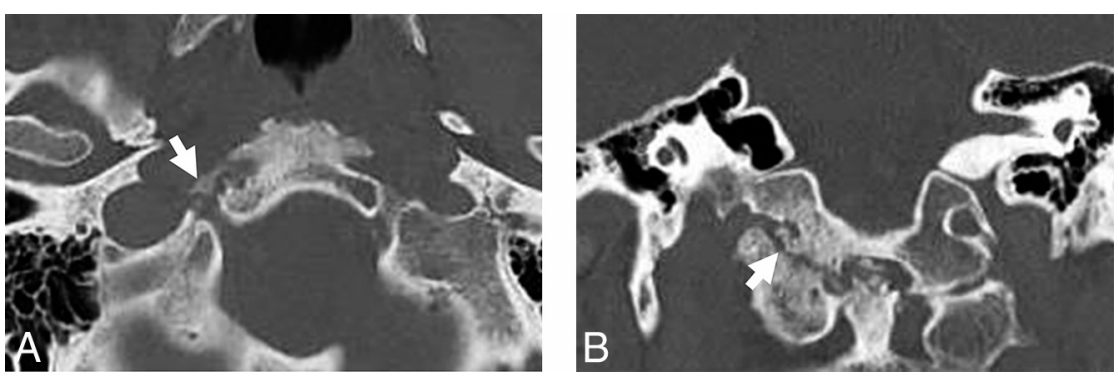

FIG 4. Cl-occipital osteophyte of patient 7. This patient was a 77-year-old man with a 3-month history of tongue weakness and dysarthria. CT axial $(A)$ and coronal $(B)$ images show severe $\mathrm{Cl}$-occipital arthrosis with osteophyte encroachment at the hypoglossal canal external ostium (arrows).

palsy with advanced CCJDD had C1-occipital joint osteophyte encroachment on the ipsilateral hypoglossal canal external ostia. In these patients, C1-occipital arthrosis and osteophytes narrowed the hypoglossal canal and caused erosions of its walls. The osteophytes appeared hypointense on T1- and T2weighted MR imaging, and hyperattenuated on CT (Fig 4). Degenerative osteophyte encroachment on the hypoglossal canal was correctly identified within the initial radiology report for 1 patient. For the other patient, the offending osteophyte was not seen, though tongue hemiatrophy was noted in the radiology report.

\section{Surgical Correlation}

Four patients underwent surgical treatment for hypoglossal nerve compression by CCJ JACs. Two patients had atlanto-occipital JAC resection, with pathologic evaluation confirming synovial cysts. In another 2 patients with CCJ JAC, the hypoglossal palsy was considered irreversible, and occipital-C2 posterior fusion was performed to prevent additional cranial nerve injury by potential cyst enlargement. Postfusion MRI demonstrated resolution of 1 atlanto-occipital JAC and decreased size for the other. Surgery was not performed in patients with hypoglossal palsy caused by underlying ROFPs or osteophytes.

\section{DISCUSSION}

Hypoglossal nerve palsy is uncommon, and diagnosis of the underlying cause can be problematic for clinicians and radiologists. High-resolution imaging and a detailed understanding of twelfth cranial nerve anatomy are critical to the identification of causative lesions and to formulating an educated differential diagnosis. Overall, tumors are the most common cause of hypoglossal nerve palsy, accounting for nearly 50\% of cases. ${ }^{1}$ Hypoglossal nerve palsy secondary to premedullary cistern or hypoglossal canal pathology is most frequently caused by hematogenous skull base metastasis. Skull base invasion of nasopharyngeal carcinoma, radiation-induced neuropathy, hypoglossal neuritis, and schwannomas or secondary nerve compression by meningioma, aneurysm, arachnoid cyst, and occipital condyle fracture are also commonly included in the differential diagnosis. ${ }^{1,2,4,5,8-10}$ Our series of 18 patients with hypoglossal palsy secondary to JACs, ROFPs, and osteophytes is, to our knowledge, the largest series with underlying CCJDD pathologic causes. In this retrospective series, perceptual and interpretive errors in diagnosis led to an underreporting of these lesions as the cause for hypoglossal palsy.

\section{Juxta-Articular Cysts}

Isolated case reports have described hypoglossal palsy resulting from CCJ juxta-articular synovial ${ }^{2,4,5}$ and ganglion ${ }^{3,6-8}$ cysts arising from either the atlanto-occipital ${ }^{2-4,8}$ or the atlantoax$\mathrm{ial}^{5}$ joints. Although synovial and ganglion cysts can be distinguished histologically, differentiation by imaging is neither feasible nor clinically important. Therefore, it is practical to adhere to the convention proposed by Kao et al ${ }^{11}$ and simply identify either synovial or ganglion cysts as JACs. Spinal degeneration and segmental instability are thought to have an im- 
portant role in JAC development, having a predilection for the most mobile levels in the cervical spine. ${ }^{12}$ Our series included 1 patient with developmental occipitalization of $\mathrm{C} 1$, which might have contributed to the patient's atlantoaxial JAC formation.

Most of our patients with CCJ JAC (8/12) were women (mean age, 70.2 years; range, 52-89 years). Our findings are consistent with the female predilection ${ }^{13}$ and higher seventh-decade prevalence ${ }^{12,13}$ previously reported for lumbar spinal JACs. Of interest, though the association of headache and JAC was noted previously in a case report, ${ }^{5} 10$ of 12 patients with CCJ JAC reported new or worsening ipsilateral headache or suboccipital pain initiating in close relation to their hypoglossal palsy onset.

CCJ JACs appeared as well-defined extradural lesions with extension into the hypoglossal canal and narrow connections with the parent atlanto-occipital or atlantoaxial joint best visualized on thin-section, coronal T2-weighted images and oblique $2 \mathrm{D}$ or $3 \mathrm{D}$ reformations parallel to the hypoglossal canal. JACs were most conspicuous on T2-weighted images, where they uniformly showed a thin hypointense cyst wall and central hyperintensity. On postcontrast T1-weighted images, cysts showed only peripheral rim enhancement. These findings are consistent with those reported in a large imaging review of lumbar synovial cysts. ${ }^{13}$ On CT, CCJ JACs were mostly hypoattenuated (6/7). All CCJ JACs encroached on the hypoglossal canal internal ostium by $50 \%$ or more, with most (8/12) extending into or through the hypoglossal canal. Secondary hypoglossal canal smooth remodeling, as previously reported in lumbar JACs, ${ }^{13}$ was seen in 3 of 8 patients. Ten patients had follow-up MR imaging without intervening surgery, revealing JAC size to be enlarged in 4, unchanged in 2 , and decreased in 4 . Synovial cyst size variation has been reported previously in the lumbar spine, where decreased size ${ }^{13}$ or complete resolution ${ }^{14}$ might be attributed to diminished synovial inflammatory fluid production or spontaneous cyst rupture.

CCJ JACs that cause hypoglossal palsy can be treated with surgical resection via a lateral suboccipital craniotomy, ${ }^{2-4,7,8}$ posterior fusion, or conservative management. ${ }^{5}$ Most of our 12 patients with hypoglossal palsy caused by CCJ JAC chose conservative management because the hemiglossal palsy was clinically tolerable and considered likely irreversible. Four patients with CCJ JAC underwent surgery. Two patients with cyst resection had no change in hypoglossal palsy, though suboccipital headache decreased for 1 patient. For 2 patients who underwent occipital-C2 fusion, postoperative MRI showed that the JACs either resolved or decreased in size, though neither patient reported improvement in hypoglossal palsy symptoms or suboccipital headache. The CCJ JAC decreased size or resolution after occipital-C2 fusion supports the theory that spinal instability strongly contributes to synovial cyst formation because increased motion causes synovial inflammation and secondary fluid production.

\section{Retro-Odontoid Fibrous Pseudotumor}

Retro-odontoid soft tissue masses causing cervicomedullary compression can result from numerous diseases, including rheumatoid arthritis ${ }^{15}$ and calcium pyrophosphate deposition disease. ${ }^{16}$ Some investigators have theorized that in noninflammatory
ROFP, also known as degenerative pseudopannus, soft tissue masses composed of benign fibrous granulation tissue form in response to chronic atlantoaxial subluxation. ${ }^{17,18}$ Other investigators have reported ROFP formation in patients without overt atlantoaxial subluxation ${ }^{19,20}$ and proposed that altered biomechanics attributable to adjacent segment ankyloses cause repeated transverse ligament injury with resulting hypertrophy. None of our 4 patients with ROFP had a systemic arthritic condition. Two had previously undergone surgical cervical fixation, with resulting altered biomechanics likely contributing to chronic, excessive atlantoaxial stress.

Although most of the previously reported patients with ROFP were men, most patients in our series were women. Our mean patient age of 82 years (range, $70-87$ years) is higher than previously reported by Chikuda et al ${ }^{19}$ (mean, 72 years) and Kakutani et $\mathrm{al}^{20}$ (mean, 76 years). The most common clinical manifestation of ROFP is myelopathy secondary to ventral cervicomedullary compression. ${ }^{18-20}$ To the best of our knowledge, ROFP has not been previously reported as a cause of hypoglossal palsy. Of interest, none of our 4 patients with CCJ ROFP hypoglossal palsy had myelopathy on neurologic examination, though imaging showed ventral cervicomedullary compression in 2 of the 4 patients.

ROFPs in our series showed variable MR imaging characteristics on T1- (hypointense, 2/3; isointense, 1/3) and T2-weighted (hypointense, 2/3; mixed iso-hyperintense, 1/3) sequences. Most ROFPs have been reported as iso-hypointense on T1-weighted images and hypointense on T2-weighted images, ${ }^{17,19}$ consistent with a predominant fibrous composition. Alternatively, some ROFPs have been described on T2-weighted images as an admixture of iso-hyperintensity, ${ }^{18,20}$ perhaps reflecting a larger component of vascular granulation tissue. ROFP enhancement, variably described as "absent" and "present" in previous reports, ${ }^{18,20}$ was seen in 3 of our 4 patients. Prior studies have shown that CCJ pseudotumor mass volume can decrease after direct resection, ${ }^{17}$ occipital-cervical fusion, ${ }^{18,19}$ or C1 laminectomy, ${ }^{20}$ with secondary myelopathy commonly improved after either surgical approach. ${ }^{18-20}$

\section{Atlanto-Occipital Osteophytes}

Hypoglossal palsy secondary to atlanto-occipital osteophytes has been previously described in single-case reports. ${ }^{9,10}$ In our 2 patients with hypoglossal palsy secondary to C1-occipital osteophytes, osteophyte encroachment and secondary hypoglossal canal wall erosions were observed at the external ostium. This external canal encroachment is in contrast to ROFPs and CCJ JACs, which encroach on the internal ostium, and commonly extended within and/or through the hypoglossal canal. One of our 2 patients with C1-occipital osteophytes had underlying congenital C2-C3 vertebral body nonsegmentation. Both patients were treated conservatively because unilateral hypoglossal palsy is reasonably well tolerated, requires complex surgery with substantial morbidity, and is unlikely to regress postoperatively.

\section{Improving CCJDD Lesion Recognition and Differentiating JACs from Hypoglossal Schwannomas}

In our series, CCJDD lesions causing hypoglossal palsy were often undiagnosed at initial imaging interpretation because of percep- 
tual or interpretive errors. Among the 18 patients, perceptual errors-in which the underlying CCJ lesion was not described in the initial imaging interpretation despite radiologist notation of ipsilateral hemiglossal atrophy-were found in 4 patients ( 2 of 12 patients with JACs; 1 of 3 with ROFPs; 1 of 2 with osteophytes). Interpretive errors - in which the lesion was described in the initial imaging report, yet was not correctly specified within the differential diagnosis-occurred in 6 of the 12 patients with CCJ JAC. Therefore, hypoglossal palsy causative JAC was correctly included in the initial radiology report in only $33 \%(4 / 12)$ of our patients with JAC. The underlying lesion was correctly included in the initial radiology report's differential diagnosis in 3 of 4 ROFP cases and 1 of 2 cases of hypoglossal canal osteophyte encroachment.

Diverse MR imaging and CT techniques used at outside institutions and our tertiary medical centers during this 10-year retrospective period were seldom optimized for evaluation of twelfth cranial nerve pathologies. Contrast-enhanced CT is the most common initial imaging study for evaluating patients with hypoglossal palsy. Helical acquisition from the posterior fossa to the hyoid bone allows evaluation from the medullary hypoglossal nuclei to the end-organ intrinsic tongue, styloglossus, hyoglossus, and genioglossus muscles. Demonstration of hypoglossal canal encroachment by CCJDD lesions can be aided by small field of view, thin-section ( $\leq 2 \mathrm{~mm}$ ) axial, coronal, and sagittal soft tissue and bone reconstructions centered at the hypoglossal canal. Oblique reformations parallel to the hypoglossal canal can be helpful in assessing intracranial extension and bony erosion. In our series, CCJ JACs, the most common CCJDD lesion to cause hypoglossal palsy, were more conspicuous on MR imaging than CT. A dedicated posterior fossa-skull base MR imaging protocol, including thin-section ( $\leq 3 \mathrm{~mm})$, small field of view sequences, should be used to evaluate patients with hypoglossal palsy in whom initial enhanced neck CT is unrewarding or in whom hemiglossal atrophy is noted on routine MR imaging. Besides postcontrast T1-weighted images, T2-weighted sequences are particularly helpful in evaluating CCJ degenerative lesions. Their inclusion in all 3 planes, ideally as a high-resolution volumetric sequence, is strongly recommended.

Among our 12 patients with CCJ JACs, cystic hypoglossal schwannoma was listed within the report differential 5 times. Differentiating CCJ JACs from "cystic" hypoglossal schwannomas is challenging. In a series of 44 surgically treated hypoglossal schwannomas, Nonaka et $\mathrm{al}^{21}$ found clinical presentations similar to CCJ JACs, with a female predominance, mean patient age of 45.8 years, and symptoms including ipsilateral tongue atrophy (92\%), headache (61\%), and dysphagia (32\%). Hypoglossal schwannomas can be characterized as intracranial (31.5\%), extraand intracranial "dumbbell" (50\%), or extracranial $(18.5 \%),{ }^{22}$ with secondary hypoglossal canal enlargement reported in up to $83 \% .{ }^{21}$ So-called cystic hypoglossal schwannomas are uncommon, with cystic foci most often developing within large tumors with necrosis or spontaneous intratumoral hemorrhage. ${ }^{23,24}$ In a previous cystic hypoglossal schwannoma case report, preoperative MR imaging showed peripheral enhancement surrounding cystic regions, whereas the tumor solid component enhanced uniformly. ${ }^{23}$ Thus, hypoglossal schwannomas and CCJ JACs share identical clinical presentations, might extend into and remodel the hypoglossal canal, and appear T1 hypointense and T2 hyperintense on MR imaging. However, an extradural location at the premedullary cistern, contiguity with the atlanto-occipital or atlantoaxial joints, lobular projections inconsistent with the hypoglossal nerve course, and thin peripheral contrast enhancement without solid enhancing component are helpful in distinguishing CCJ JACs from cystic hypoglossal schwannomas. This distinction is imperative because CCJ JAC misdiagnosis as a hypoglossal schwannoma can result in mistreatment and potential morbidity of stereotactic radiosurgery or in an unwarranted intradural surgical approach with possible cranial nerve injury. ${ }^{4}$

The present study has several limitations. It is a retrospective review of a rare entity and is limited as such. Based on our method for identifying patients for review, the potential exists for missing cases in which the neuroradiologist did not include "hypoglossal palsy" or "tongue atrophy" in the radiology report. A referral bias might be present because our institution is a tertiary care center. In addition, at our large referral center, many patients had limited or no long-term follow-up after their initial evaluation. Most patients were conservatively treated, limiting surgical confirmation.

\section{CONCLUSIONS}

Though degenerative disease at the craniocervical junction is commonly seen on imaging studies, it has been rarely reported as a cause of hypoglossal palsy. JACs were a more common CCJDD causative lesion than ROFPs and osteophytes. CCJDD should be added to the list of potential hypoglossal palsy causes, and familiarity with each type of CCJ degenerative lesion and its characteristic imaging appearance should improve the diagnosis and treatment of these disorders.

\section{REFERENCES}

1. Thompson EO, Smoker WR. Hypoglossal nerve palsy: a segmental approach. Radiographics 1994;14:939-58 CrossRef Medline

2. Mujic A, Hunn A, Liddell J, et al. Isolated unilateral hypoglossal nerve paralysis caused by an atlanto-occipital joint synovial cyst. J Clin Neurosci 2003;10:492-95 CrossRef Medline

3. Baldauf J, Junghans D, Schroeder HW. Endoscope-assisted microsurgical resection of an intraneural ganglion cyst of the hypoglossal nerve. J Neurosurg 2005;103:920-22 CrossRef Medline

4. Elhammady MS, Farhat H, Aziz-Sultan MA, et al. Isolated unilateral hypoglossal nerve palsy secondary to an atlantooccipital joint juxtafacet synovial cyst. J Neurosurg Spine 2009;10:234-39 CrossRef Medline

5. Mendes-Araújo L, Rangel C, Domingues RC, et al. Case report: atlantoaxial synovial cyst causing isolated unilateral hypoglossal nerve paralysis. Br J Radiol 2010;83:e35-38 CrossRef Medline

6. Nonaka Y, Grossi PM, Filomena CA, et al. Unilateral hypoglossal nerve palsy caused by an intraneural ganglion cyst. J Neurosurg 2010;113:380-83 CrossRef Medline

7. Gambhir S, Mujic A, Hunn A. An intraneural ganglion cyst causing unilateral hypoglossal nerve palsy. J Clin Neurosci 2011;18:1114-15 CrossRef Medline

8. Bilgin-Freiert A, Fugleholm K, Poulsgaard L. Case report: intraneural intracanalicular ganglion cyst of the hypoglossal nerve treated by extradural transcondylar approach. J Neurol Surg Rep 2015;76: e180-82 CrossRef Medline

9. Patron V, Roudaut PY, Lerat J, et al. Isolated hypoglossal palsy due to cervical osteophyte. Eur Ann Otorhinolaryngol Head Neck Dis 2012;129:44-46 CrossRef Medline

10. Patro SN, Torres C, Riascos R. An unusual case of isolated hypoglos- 
sal nerve palsy secondary to osteophytic projection from the atlanto-occipital joint. Neuroradiol J 2014;27:361-64 CrossRef Medline

11. Kao CC, Winkler SS, Turner JH. Synovial cyst of spinal facet: case report. J Neurosurg 1974;41:372-76 CrossRef Medline

12. Boviatsis EJ, Stavrinou LC, Kouyialis AT, et al. Spinal synovial cysts: pathogenesis, diagnosis and surgical treatment in a series of seven cases and literature review. Eur Spine J 2008;17:831-37 CrossRef Medline

13. Apostolaki E, Davies AM, Evans N, et al. MR imaging of lumbar facet joint synovial cysts. Eur Radiol 2000;10:615-23 CrossRef Medline

14. Swartz PG, Murtagh FR. Spontaneous resolution of an intraspinal synovial cyst. AJNR Am J Neuroradiol 2003;24:1261-63 Medline

15. Casey AT, Crockard HA, Pringle J, et al. Rheumatoid arthritis of the cervical spine: current techniques for management. Orthop Clin North Am 2002;33:291-309 CrossRef Medline

16. Patel NP, Wright NM, Choi WW, et al. Forestier disease associated with a retroodontoid mass causing cervicomedullary compression. J Neurosurg 2002;96(2 suppl):190-96 CrossRef Medline

17. Sze G, Brant-Zawadzki MN, Wilson CR, et al. Pseudotumor of the craniovertebral junction associated with chronic subluxation: MR imaging studies. Radiology 1986;161:391-94 CrossRef Medline

18. Yamaguchi I, Shibuya S, Arima N, et al. Remarkable reduction or disappearance of retroodontoid pseudotumors after occipitocervi- cal fusion: report of three cases. J Neurosurg Spine 2006;5:156-60 CrossRef Medline

19. Chikuda H, Seichi A, Takeshita K, et al. Radiographic analysis of the cervical spine in patients with retro-odontoid pseudotumors. Spine (Phila Pa 1976) 2009;34:E110-14 CrossRef Medline

20. Kakutani K, Doita M, Yoshikawa M, et al. C1 laminectomy for retroodontoid pseudotumor without atlantoaxial subluxation: review of seven consecutive cases. Eur Spine J 2013;22:1119-26 CrossRef Medline

21. Nonaka Y, Grossi PM, Bulsara KR, et al. Microsurgical management of hypoglossal schwannomas over 3 decades: a modified grading scale to guide surgical approach. Neurosurgery 2011;69(2 suppl operative):ons121-40; discussion ons140 CrossRef Medline

22. Hoshi M, Yoshida K, Ogawa K, et al. Hypoglossal neurinoma: two case reports. Neurol Med Chir (Tokyo) 2000;40:489-93 CrossRef Medline

23. Li WC, Hong XY, Wang LP, et al. Large cystic hypoglossal schwannoma with fluid-fluid level: a case report. Skull Base 2010;20:193-97 CrossRef Medline

24. Takahashi T, Tominaga T, Sato $Y$, et al. Hypoglossal neurinoma presenting with intratumoral hemorrhage. J Clin Neurosci 2002;9: 716-19 CrossRef Medline 